\title{
Five Principles of Waste Product Redesign under the Upcycling Concept
}

\author{
Jiang $X U^{1} \&$ Ping $G U^{1}$ \\ ${ }^{1}$ School of Design, Jiangnan University, Wuxi, China
}

\begin{abstract}
KEYWORD: Upcycling; Redesign principle; Green design; Industrial design; Product design
ABSTRACT: It explores and constructs the principles of waste product redesign which are based on the concept of upcycling. It clarifies the basic concept of upcycling, briefly describes its current development, deeply discusses its value and significance, combines with the idea of upcycling which behinds regeneration design principle from the concept of " $4 \mathrm{R}$ " of green design, and takes real-life case as example to analyze the principles of waste product redesign. It puts forward five principles of waste product redesign: value enhancement, make the most use of waste, durable and environmental protection, cost control and populace's aesthetic.
\end{abstract}

\section{INTRODUCTION}

Recently, environmental problems was becoming worse and worse, while as a developing country, China is facing dual pressures that economical development and environmental protection. However, large numbers of goods become waste every day all over the world, but the traditional recycling ways, such as melting down and restructuring, not only produce much $\mathrm{CO}_{2}$, but also those restructured parts or products cannot mention in the same breath with raw ones. As a result, the western countries started to center their attention to the concept of "upcycling" of green design, which can transfer the old and waste things into more valuable products to vigorously develop the green economy. Nevertheless, this new concept hasn't been well known and the old notion of traditionally inefficient reuse still predominant in China, so it should be beneficial for our social development to construct the principles of waste products' redesign which are based on the concept of upcycling.

\section{THE CONCEPT OF UPCYCLING}

The word "upcycling" origined from a news manuscript of Thornton Kay interviewed Reiner Pilz in 1994, in such an article, Reiner Pilz called the existing recycling as "downcycling", as well appalled "upcycling" which can strength the value of the waste products (Kay, 1994). And in 1999, a book named "upcycling" from two Germans, Gunter Pauli and Johannes F. Hartkemeyer, the former was a famous enterpriser and also the initiator of "the Blue Economy", and the latter was the director of Osnabruck community college. Then in 2002, William McDonough and Michael Braungart clarified the concept of "upcycling" in a book named Cradle to Cradle: Remaking the Way We Make Things, which has caused extensive attention of academic community. They also stated that the goal of upcycling is to prevent wasting potentially useful materials by making use of existing ones. In order to reduce the consumption of new materials and energy, the pollution of air and water, and even the emission of greenhouse gases.

\section{THE DEVELOPMENTAL SITUATION OF UPCYCLING}

\section{The dimension of the design}

Recent years, the concept of "upcycling" is more and more popular in the world. For example, the number of products on Etsy tagged with the word "upcycled" increased from about 7,900 in January 2010 to nearly 30,000 a year later - an increase of 275 percent (Wang, 2011). As of April 2013, that number stood at nearly 263,685, an additional increase of 879 percent (Rodengorg, 2013). However, it still hasn't formed a large-scale market of redesign in china, but some typical cases of redesign appeared. WEI Minghui, a graduate from the graphic design profession of Tsinghua University, who has made kinds of bags and suitcases out of cloth from wasting and old advertising light boxes and 
store signs, which has earned him five million yuan in three years and provided him with his own designing brand called "neicun" redesign. Although Wei hasn't adopted uprecycling as advertising slogan of his works, he subtly and efficiently used oddments to avoid twice waste has typically reflected the concept of uprecycling.

\section{The dimension of technique}

Promoting to upcycle the waste in terms of technique is adored by some chemical material scientists, the most typical case is American scientist's upcycling of chicken feathers. In 2005, the agricultural research and service lab of United States agriculture department developed a new patent which to make the textile fiber cloth, vessel, plastic film, plastic wraps and other certain plastic things out of chicken feather powder, whose theory is to rearrange the molecular structure of kerantin the main element of chicken feathers, in order to produce scrims with different length and width and plastic films with kinds of shapes. It was reported that this new material was strong, light and biodegradable, as well had no pollution to the environment. Moreover, the research of using chicken feathers to produce bioplastics has had new breakthroughs recent years. Such as in 2011, American Chemical Society national exhibition conference has showed the researching result of Yiqi Yang, a biological materials and biological fiber experts from the college of agricultural sciences and natural resources, University of Nebraska-Lincoln, the report was about using chicken to make thermo-plastic and had proved that this kind of thermo-plastic can keep its stability performance in water, as well its stable mechanical properties. This breakthrough has added new commercial value to "chicken feather plastics", meanwhile, provided more designing space and chances for the designers.

\section{THE VALUE AND SIGNIFICANCE OF UPCYCLING}

"Upcycling" is the advanced stage of cyclic utilization, a kind of value-added reproduce of wasted or old materials, and also the redesigning target of green design. China as the biggest developing country in the world, the waste and garbage is multiplying daily, and its gross carbon emission takes the first all over the world, so it must be beneficial for china's constructing resource conservation and environment friendly society to upcycle wasted or old materials. Moreover, "upcycling" also has its potential economical value, for the "upcycling" target is wasted or old materials which cost low, and the "upcycling" technique can give its more additional value. Therefore, with proper ways, the wasted can also be upgraded to be treasures to create considerable economic benefits.

\section{THE ORIGIN OF "RECYCLING" PRINCIPLE OF GREEN DESIGN}

For industrial design, the core idea of green design is " $3 \mathrm{R}$ " principle, namely, reducing, reusing and recycling, which not only requires cutting down the consume of energy and materials, reducing the emission of hazardous substance, but also asks for its products and parts that could be convenient for separation and collection, for reuse or recycle. On the basis of "3R" principle and low carbon idea that popular among all people, the modern green design proposes a new " $4 \mathrm{R}$ " concept to detail recycle as two parts: recycle and regeneration (see figure 1). 


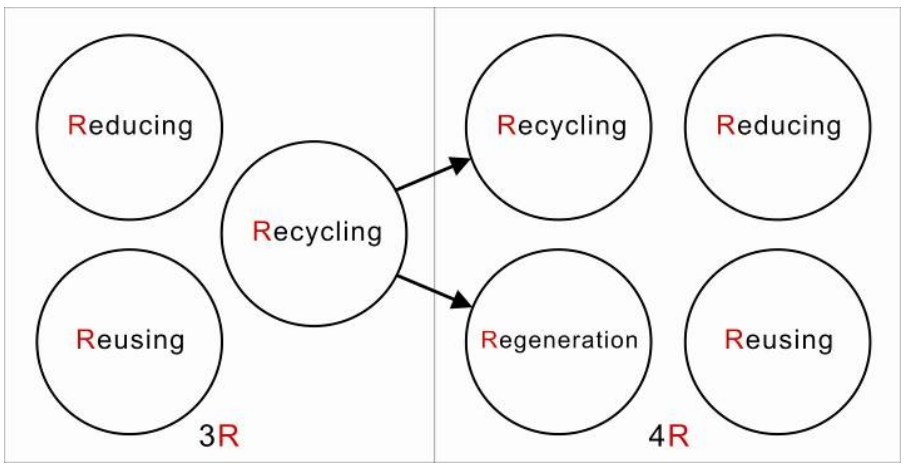

Figure 1. From "3R" to "4R"

As the part of regeneration, Ruize Du concluded its principles as following four aspects in his book named "product durable design": (1) apply surface treatment to simply recycle materials; (2) use structure design to remedy the deficiency of recycling materials; (3) take the advantage of the feature of secondary materials to design; (4) try best not to add any other natural materials (Du, 2002).

It is observed that with the principle change from " $3 \mathrm{R}$ " to " $4 \mathrm{R}$ ", the design concept from probably simplify, classify, streamline to finer transformation and regeneration. Meanwhile, prolonging service life, enhancing after-service quality, excavating same structure applying potential, strengthening structural design to remedy the deficiency of recycling materials, and trying best not to add any other natural materials all means the design has started to pay attention to energy cycle of productive process, as well abstinence and prolong product service life in consumption process at its origin (Wang and $\mathrm{Su}, 2013$ ). It is not hard to know that the recycling principle of " $4 \mathrm{R}$ " concept had revealed some design concept of upgrade regeneration, which provides essentially theoretical support for us to study the redesign principle of the waste.

\section{THE REDESIGN PRINCIPLE OF THE WASTE BEHIND REGENERATION DESIGN PRINCIPLE}

\section{Value enhancing principles}

The core target of upcycle is to promote the value of the waste and turn it to be wealth, so enhancing its value should take the first. Such a principle requires designers deeply excavate the potential value of the waste from its function, material, structure and so on, and make their utmost to amplify its value.

\section{The principle of making the most use of the waste}

Redesigning with the waste as raw material should try our best to reduce the scrap materials from manufacturing process in order to make the most use of the waste and avoid secondary waste. Which needs the designers to start from the source to make an reasonable programming of the whole design and manufacturing process, as well equipped with sound control ability of dealing with emergencies. However, not every redesign of the waste can make its most use. Therefore, how to cut down the production and take proper management of the waste as much as possible needs the designers with certain environmental awareness.

\section{Durable and environmental principle}

Although the raw material of redesigning products comes from wasted or old things, it doesn't mean such products' quality is poor. On the contrary, the designers should treat it equally without discrimination, and develop it with the same status of regular products in order to ensure its durable quality and prolong its service life. Meanwhile, the designers should pay more attention to take the environmentally friendly products as design guide, and avoid negative influence to environment in the process of products' design, use and recycle. 


\section{Cost control principle}

While recycle and redesign of the waste should take an efficiently cost control, or products cannot translate to goods successfully and its value will sharply reduce. So design as the first step of the regeneration, the designers should take all points of designing process into consideration, so as to efficiently control the cost of redesign from the source.

\section{Populace's aesthetic principle}

Conforming to the public's aesthetic taste should follow the design principle of taking commercialization as guide. Under such a principle, the designers should possess perfect visual quality, keen insight and be familiar with conditions and customs of target market, as well be sensitive with fashionable and popular elements. And try their best to avoid taking personal thoughts and value into the design to make it as an individual "toy", but not to conform to the public's aesthetic taste.

\section{THE ANALYSIS OF TYPICAL UPCYCLING CASES}

FREITAG is an environmental bags manufacturer in Switzerland Zurich with integrating design, production and distribution, which was found in 1993 by Freitag brothers, Markus and Daniel. Whose bags and luggages are all created from the waste, while the worn-out waterproof cloth of container truck as their main material, the waste car seat belts made as their straps or portable belt, and the inner tube of bike as their accessories, as shown in figure. 2 and 3 (which comes from official web of FREITAG).

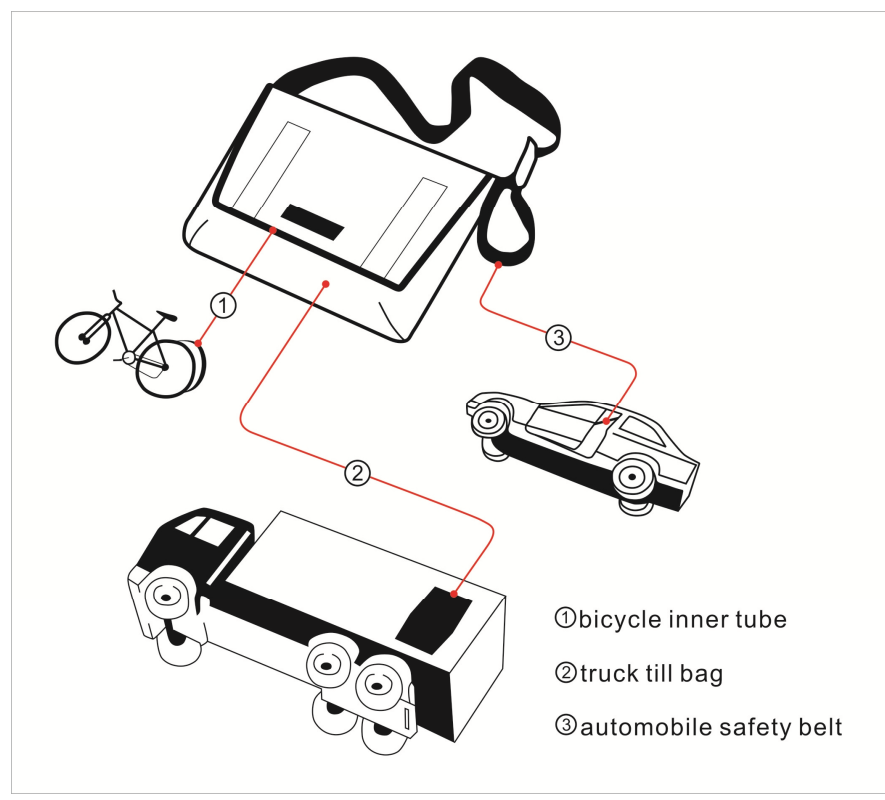

Figure 2. The source FREITAG bag's materials

By ingenious redesign, FREITAG transfers the waste into fashionable bags which give an excellent perspective of redesign principle of the waste under the upgrade regeneration. Firstly, to the point of value enhancing, FREITAG makes fashionable products out of seemly ordinary waste products, see figure.2 (which comes from official web of FREITAG), transfers the "recycling" raw material to be consumptive products, which can not only cut down the energy consumption of dealing with the waste, but also greatly promote its value. 


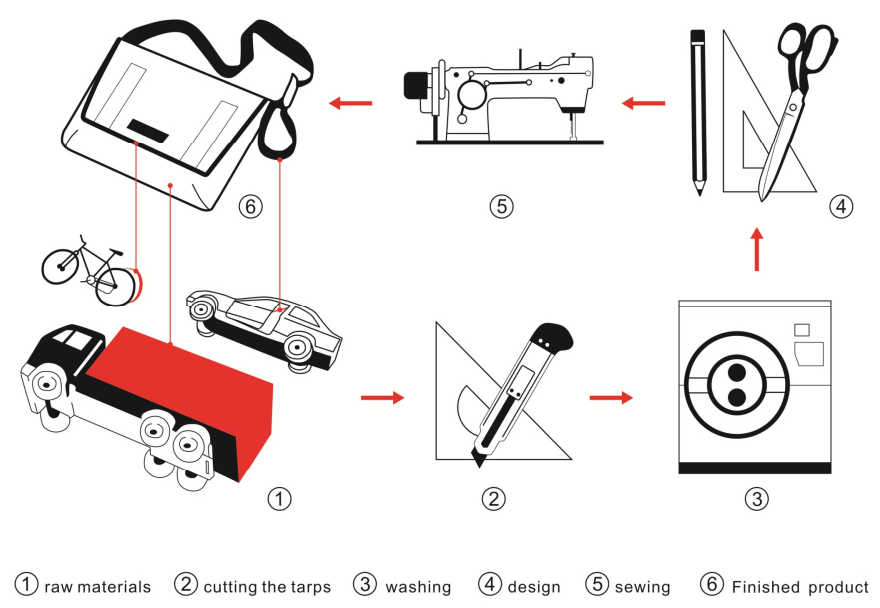

Figure.3 FREITAG products

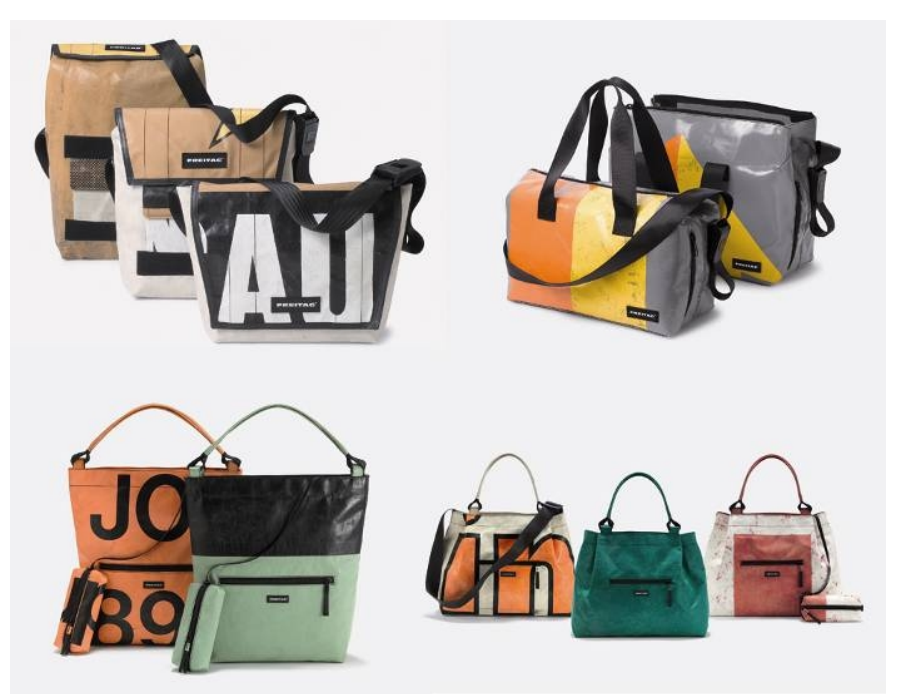

Figure.4 the process of FREITAG bag's production

Secondly, as to the waste materials' using condition of FREITAG, which not only making the most Use of the waste, but also stick to the design principle of durable and environmental. The former is mainly reflected in FREITAG's using of oddments; those leftover materials trimmed from manufacturing large haversacks will be processed as pocket bags or ticket folders, or accessories of other large bags. The later is embodies in its chosen of raw material, for waterproof cloth of container truck, inner tube of bike and car seat belts are all wear-resisting and anti-aging.

Lastly, as far as the market is concerned, FREITAG not only control the cost efficiently, but also conform to the public's aesthetic taste. The process of FREITAG's products from raw materials' acquired to its completed, which can divides into five steps, see figure.4 (which was drew by the author), namely, obtain, clipping, wash, design and sewing (manufacture) of raw materials, just as that of regular materials. From the aspect of public's aesthetic taste, FREITAG makes the most of the painting on the waterproof cloth of container truck to endow it with fashionable colors (see figure.2). For the differences of every waterproof cloth's painting, and even the same one, the designers will consciously avoid the repetition of dermatoglyphic pattern, so the surface detail of every FREITAG's bag is unique, which can satisfy consumers' aesthetic taste as much as possible. 


\section{CONCLUSION}

Upcycling has been a design tendency in western design and manufacturing industry, while our country who is facing more and more serious environmental problems, but the word "upcycling" is still unpopular among the design community. However, to deal with recycling problem of wasted products or materials, we should be equipped with the prerequisite concept of upcycling the worn-out products or materials. Researching on the redesign principle of the waste under the upcycling concept will benefit to us to understand the target and meaning of upcycle, and has a certain guiding significance for design and practice.

\section{REFERENCES}

[1] Du, R. 2002. Product Durable Design. Taipei: The Pacific book publishers.

[2] Kay, T. 1994. Salvo in Germany-Reiner Pilz. SalvoNEWS (99), pp11-14.

[3] Rodengorg, R. 2013. Upcycle Trend Hits Faribault Area. Faribault Daily News, http://www.southernminn.com/faribault_daily_news/news/article_a8276afa-e288-50f3-8573203e788f9366.html.

[4] Wang, J. 2011. Upcycling Becomes a Treasure Trove for Green Business Ideas. Entrepreneur Magazine. http://www.entrepreneur.com/article/219310.

[5] Wang, Y. L. \& Su, X. 2013. New Concept of Green Design Based on "Low Carbon Life". Packaging Engineering, 35(12), 87-90. 